\title{
Evaluation of knowledge, attitude and practice of pharmacovigilance among interns and nursing students in a tertiary care teaching hospital
}

\author{
Sudhir R. Pawar, Nitin C. Gawari, Jaisen M. Lokhande*
}

Department of Pharmacology, LTMMC and GH, Sion Mumbai, India

Received: 10 February 2020

Revised: 19 March 2020

Accepted: 20 March 2020

\section{*Correspondence:}

Dr. Jaisen M Lokhande,

Email: dr_jaisen@ hotmail.com

Copyright: (c) the author(s), publisher and licensee Medip Academy. This is an open-access article distributed under the terms of the Creative Commons Attribution Non-Commercial License, which permits unrestricted non-commercial use, distribution, and reproduction in any medium, provided the original work is properly cited.

\section{ABSTRACT}

Background: Even though the role of spontaneous reporting of adverse drug reactions (ADRs) is well established in pharmacovigilance, it is not followed in the practice and a large number of ADRs goes unreported. In our institute, almost all of the ADR reported to the department of pharmacology are through either the faculty members or the residents and very few by the nurses and interns.

Methods: The current survey was thus conducted to assess the knowledge, attitude and practice (KAP) of nursing students and interns. It is expected that the results should help us to designs specific activities to improve ADR reporting. The study was a questionnaire based survey to assess the knowledge, attitude and practices (KAP) of the interns $(n=74)$ and nursing students $(n=108)$ regarding ADR reporting and pharmacovigilance in this tertiary care centre.

Results: More interns gave correct responses to knowledge based and attitude based questions of pharmacovigilance compared to the nursing students. On the other hand, more nursing students came across ADRs in the patients compared to interns. Even though $93.24 \%$ interns responded to have got training on "how to report ADRs", only $6.76 \%$ ever reported ADR to pharmacovigilance centre.

Conclusions: Proper training on pharmacovigilance, with easy way for reporting ADRs would be a useful step in improving pharmacovigilance status in nursing students and interns.

Keywords: Attitude, Interns, Knowledge, Nursing students, Pharmacovigilance, Practices

\section{INTRODUCTION}

According to World Health Organization (WHO), adverse drug reactions (ADRs) is defined as 'any noxious, unintended and undesired effect of the drug that occurs at doses used for prophylaxis, diagnosis or cure of a disease'. ${ }^{1}$ ADRs are one of the leading causes of morbidity and mortality. ADRs are reported to be the $4^{\text {th }}$ $6^{\text {th }}$ leading cause of death in United States of America. ${ }^{2}$ It has been estimated that around 2.9-5.6\% of all hospital admissions are due to ADRs and as many as $35 \%$ of patients experience an ADR during their hospitalization. ${ }^{3}$ A study from South India revealed that $0.7 \%$ of hospital admissions were due to ADRs and a total of $3.7 \%$ hospitalized patients experienced ADRs, of which death accounts for $1.3 \% .^{4}$ The important point to be noted is that as per various studies, about one third of ADRs were preventable. ${ }^{5,6}$

Monitoring and also reporting of ADRs are very important in identifying the trends of adverse reaction which helps to minimize or prevent harm to patients arising from drugs. Spontaneous reporting of ADRs has remained the cornerstone of pharmacovigilance and is important in maintaining patient safety. Even though the importance of ADR reporting has been established, the 
activity is overshadowed by under-reporting of ADRs, which is a common problem in pharmacovigilance. ${ }^{7}$ As per a study, reporting of serious ADRs rarely exceeds $10 \%{ }^{8}$ The high rate of underreporting is a matter of great concern which can delay the detection of serious ADRs and consequently have a major negative impact on the public health. This underreporting may be due to lack of adequate knowledge, attitude and practice among healthcare professionals towards ADR reporting. ${ }^{9}$ Other reasons cited by health care workers were constraints of time for reporting the ADRs, few didn't knew which ADRs are to be reported, non-availability of ADR reporting forms, etc, to name a few. ${ }^{10}$

All healthcare professionals can report an ADR by filling an ADR reporting form provided by Central Drug Standard Control Organization (CDSCO). In a country like India, with a large population, contribution to ADR reporting from interns and nurses are equally important. Our institute is also one of the ADR monitoring centre (AMC) since about 8 years now and contributes to pharmacovigilance. It has been observed that most of the ADRs are reported by the faculty members and the residents and very few of the ADR reporting is contributed from the nurses and interns. Thus, the opinions and understanding of hospital nurses and interns on the issues of reporting the ADRs and the ways to solve them are very important. This survey was conducted to assess the knowledge, attitude and practice (KAP) of nursing students and interns in our institute so as to take appropriate measures to improve ADR reporting by these healthcare professionals. It is also expected that the results of this study may benefit other institutes also and appropriate measures can be taken.

Aim of study was to evaluate the baseline knowledge, attitude and practices (KAP) of the interns and nursing students regarding ADR reporting and pharmacovigilance.

\section{METHODS}

This was a cross sectional, questionnaire based study in interns and nursing students, conducted in Lokmanya Tilak Municipal General Hospital from February 2017 to July 2017.

Table 1: Knowledge, attitude and practices (KAP) questionnaires for interns and nursing students to evaluate pharmacovigilance processes.

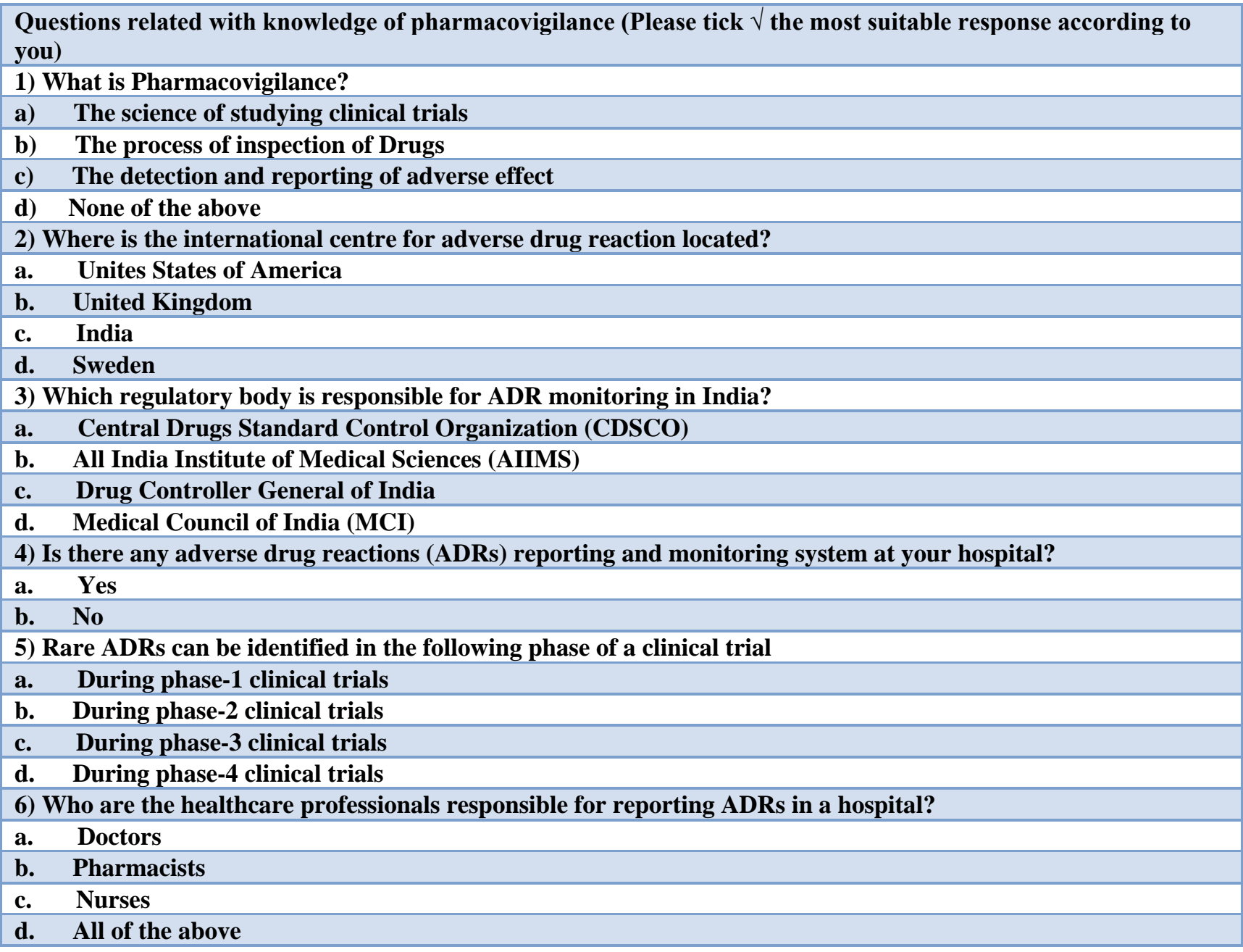




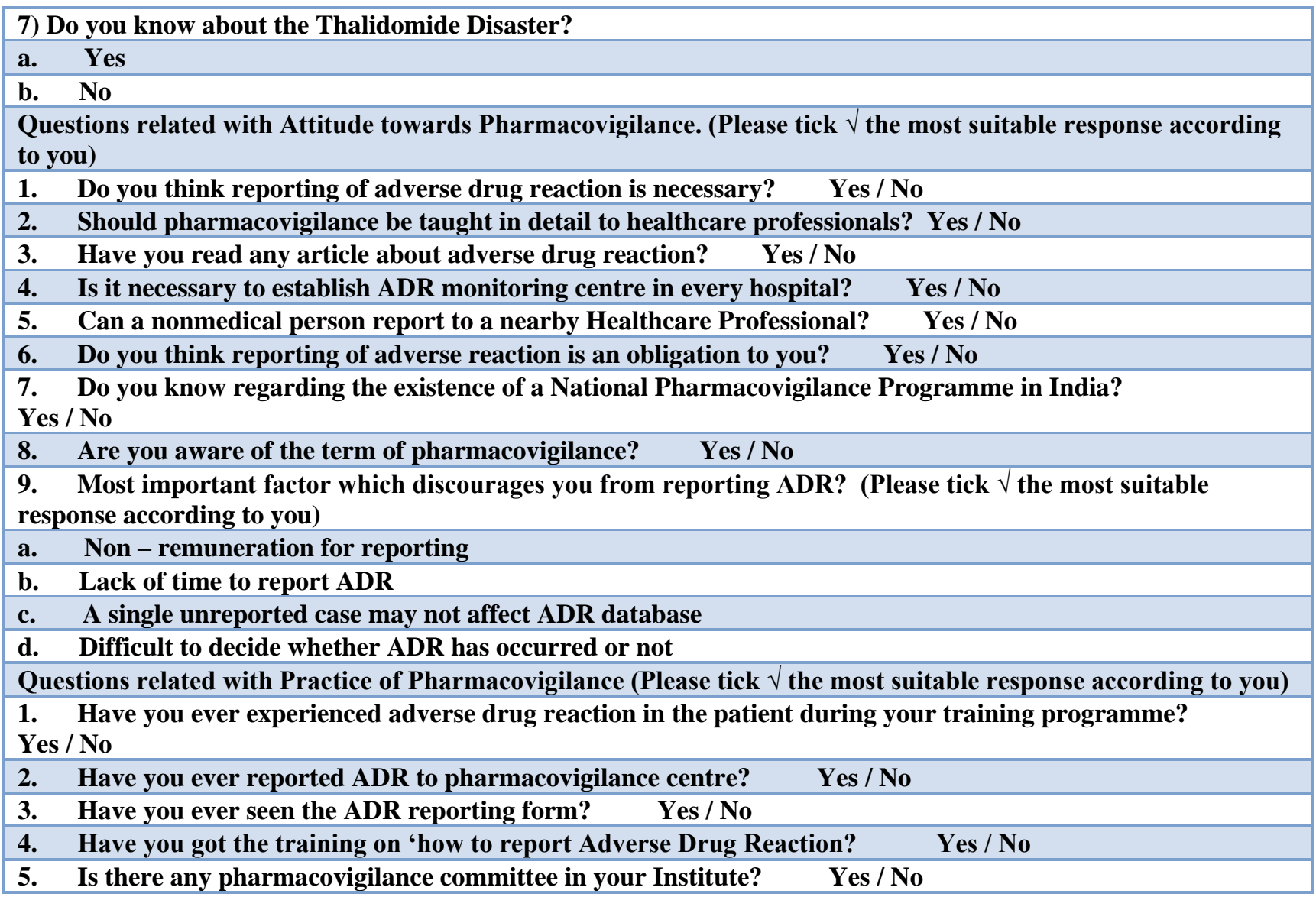

Institutional Ethical committee approval was taken before start of the study. 2nd year nursing students who had started with the clinical postings and interns who had completed at least 10 months of their internship programme and willing to provide responses to the knowledge, attitude and practices based questionnaire were included in the study. Nursing students and interns who were not willing to participate in this study were excluded. The study was planned to be conducted in 150 second year nursing students and 100 interns in a tertiary healthcare centre in Mumbai.

The KAP questionnaires (Table 1) consisted of total 21 questions. Out of which 7 were related to knowledge, 9 were related to attitude and 5 were related to practice of pharmacovigilance. The questionnaires were distributed among the nursing students and interns with the instruction to fill up the answers and submit within 25 minutes of time duration. The following questionnaires were included in the current study which were prepared based on previous published studies. ${ }^{11-13}$

\section{Statistical analysis}

The filled KAP questionnaires were analysed by producing descriptive statistics. Descriptive statistical analyses such as frequencies and percentages were used to represent the respondents' information. Data were analysed using descriptive statistics with Microsoft excel for windows 10 .

\section{RESULTS}

Interns and nursing student of the tertiary care hospital were approached for getting the response for the questionnaire. 74 interns and 108 student nurses agreed to fill up the form (Table 2). Thus, we could collect the information from a total 182 budding medical professionals.

As per the responses, more interns gave favourable/ correct responses to the knowledge based questions including meaning of pharmacovigilance $(91.9 \%$ by interns gave correct answers versus $47.22 \%$ by nursing students) and the regulatory body responsible for ADR monitoring in India $(78.38 \%$ by interns versus $44.45 \%$ by nursing students). However surprisingly only $17.57 \%$ interns felt that reporting ADRs is the responsibility of all the healthcare professionals compared to $82.41 \%$ by nursing students. Other responses did not appear to be very much differing (Table 3 ).

The attitude of the nursing students regarding pharmacovigilance was better compared to their own responses on knowledge based questionnaires. Interns 
also scored better on the attitude towards pharmacovigilance as shown in the Table 4. Regarding the important factors which discourages from reporting ADR, nursing students and interns both had difficulty to decide whether ADR has occurred or not or if it was a part of the disease. "Lack of time" for ADR reporting was the second highest response for the nursing students and interns both (Table 4).

Regarding the questionnaires for practices on pharmacovigilance, more nursing students had experienced and reported ADR compared to interns
(Table 5). Even though 93.24\% interns responded to have got training on 'how to report ADRs only $6.76 \%$ ever reported ADR to pharmacovigilance centre (Table 5).

Table 2: Details of the interviewees involved in the study.

\begin{tabular}{|llll|} 
& Males & Females & Total \\
\hline Student nurses & 0 & 108 & 108 \\
\hline Interns & 26 & 48 & 74 \\
\hline Total & 26 & 156 & 182 \\
\hline
\end{tabular}

Table 3: Responses of knowledge based questionnaires from nursing students and interns.

\begin{tabular}{|c|c|c|}
\hline Knowledge based questionnaires & $\begin{array}{l}\text { Nursing students (\% } \\
\text { with favourable } \\
\text { response) }\end{array}$ & $\begin{array}{l}\text { Interns (\% with } \\
\text { favourable response) }\end{array}$ \\
\hline 1. What is pharmacovigilance? & 47.22 & 91.9 \\
\hline 2. Where is the international centre for ADR located? & 17.59 & 5.41 \\
\hline $\begin{array}{l}\text { 3. Which regulatory body is responsible for ADR monitoring in } \\
\text { India? }\end{array}$ & 44.45 & 78.38 \\
\hline $\begin{array}{l}\text { 4. Is there any adverse drug reactions (ADRs) reporting and } \\
\text { monitoring system at your hospital? }\end{array}$ & $\begin{array}{l}74.07 \% \text { responded as } \\
\text { "Yes" }\end{array}$ & $\begin{array}{l}87.84 \% \text { responded } \\
\text { as "Yes" }\end{array}$ \\
\hline $\begin{array}{l}\text { 5. Rare ADRs can be identified in the following phase of a clinical } \\
\text { trial }\end{array}$ & 18.52 & 25.68 \\
\hline $\begin{array}{l}\text { 6. Who are the healthcare professionals responsible for reporting } \\
\text { ADRs in a hospital? }\end{array}$ & 82.41 & 17.57 \\
\hline 7. Do you know about the Thalidomide Disaster? & $\begin{array}{l}87.04 \% \text { responded as } \\
\text { "Yes" }\end{array}$ & $\begin{array}{l}90.54 \% \text { responded } \\
\text { as "Yes" }\end{array}$ \\
\hline
\end{tabular}

Table 4: Responses of attitude based questionnaires from nursing students and interns.

\begin{tabular}{|c|c|c|}
\hline Attitude based questionnaires & $\begin{array}{l}\text { Nursing students ( } \% \\
\text { with response as "yes") }\end{array}$ & $\begin{array}{l}\text { Interns ( } \% \text { with } \\
\text { response as } \\
\text { "yes") }\end{array}$ \\
\hline 1. Do you think reporting of adverse drug reaction is necessary? & 96.3 & 95.95 \\
\hline $\begin{array}{l}\text { 2. Should pharmacovigilance be taught in detail to healthcare } \\
\text { professionals? }\end{array}$ & 94.45 & 97.3 \\
\hline 3. Have you read any article about adverse drug reaction? & 64.81 & 91.9 \\
\hline $\begin{array}{l}\text { 4. Is it necessary to establish ADR monitoring centre in every } \\
\text { hospital? }\end{array}$ & 93.52 & 83.78 \\
\hline $\begin{array}{l}\text { 5. Can a nonmedical person report to a nearby healthcare } \\
\text { professional? }\end{array}$ & 89.81 & 93.24 \\
\hline $\begin{array}{l}\text { 6. Do you think reporting of adverse reaction is an obligation to } \\
\text { you? }\end{array}$ & 49.07 & 10.81 \\
\hline $\begin{array}{l}\text { 7. Do you know regarding the existence of a National } \\
\text { Pharmacovigilance Programme in India? }\end{array}$ & 66.67 & 90.54 \\
\hline 8. Are you aware of the term of pharmacovigilance? & 80.56 & 95.95 \\
\hline \multicolumn{3}{|c|}{ 9. Most important factor which discourages you from reporting ADR? } \\
\hline a. Non - remuneration for reporting & 12.04 & 2.70 \\
\hline b. Lack of time to report ADR & 35.19 & 16.22 \\
\hline c. A single unreported case may not affect ADR database & 17.59 & 16.22 \\
\hline d. Difficult to decide whether ADR has occurred or not & 35.19 & 64.86 \\
\hline
\end{tabular}


Table 5: Responses of practice based questionnaires from nursing students and interns.

\begin{tabular}{|lll|}
\hline $\begin{array}{l}\text { Practice based } \\
\text { questionnaires }\end{array}$ & $\begin{array}{l}\text { Nursing } \\
\text { students } \\
(\% \text { with } \\
\text { response } \\
\text { as "Yes") }\end{array}$ & $\begin{array}{l}\text { Interns (\% } \\
\text { with } \\
\text { response as } \\
\text { "Yes") }\end{array}$ \\
$\begin{array}{l}\text { 1. Have you ever } \\
\text { experienced adverse drug } \\
\text { reaction in the patient } \\
\text { during your training } \\
\text { programme? }\end{array}$ & 79.63 & 33.78 \\
\hline $\begin{array}{l}\text { 2. Have you ever reported } \\
\text { ADR to pharmacovigilance } \\
\text { centre? }\end{array}$ & 54.63 & 6.76 \\
\hline $\begin{array}{l}\text { 3. Have you ever seen the } \\
\text { ADR reporting form? }\end{array}$ & 52.78 & 43.24 \\
\hline $\begin{array}{l}\text { 4. Have you got the } \\
\text { training on 'how to report } \\
\text { ADR? }\end{array}$ & 54.63 & 93.24 \\
\hline $\begin{array}{l}\text { 5. Is there any } \\
\text { pharmacovigilance } \\
\text { committee in your } \\
\text { Institute? }\end{array}$ & 73.15 & 91.89 \\
\hline
\end{tabular}

\section{DISCUSSION}

The present study was a questionnaire-based survey conducted to assess the knowledge, attitude and practice of pharmacovigilance towards ADR reporting among nursing students and interns working in a tertiary care teaching hospital.

The questionnaire had 21 questions in total. The knowledge-based questions assessed, various aspects of pharmacovigilance such as knowledge of location of local and national ADR monitoring centres, people who can report and how ADR reporting done, etc. The attitude based-questions assessed the view of the participants regarding the impact of ADR, current system of Pharmacovigilance, obligation towards ADR reporting and reasons which discourages from ADR reporting. The practice based-questions determined the actual practices of reporting ADR.

As per the responses, even though the interns scored overall better in terms of knowledge and attitude compared to nursing student, they scored lesser in general, in the practice based questionnaire regarding ADR reporting. Since the theoretical knowledge on pharmacovigilance is part of curriculum for the interns, they are well versed with the knowledge on pharmacovigilance. Nursing students on the other hand also showed reasonably good response to the knowledge based questions. In our institute, the Pharmacology department is actively involved in ADR monitoring and conducts various activities including training the interns and also for the nurses and organizes conferences on pharmacovigilance topics to sensitize all the healthcare professionals of the institute. This may be one of the reasons for the better knowledge of the nursing students. The most important finding in the present study was the better response regarding the practice about pharmacovigilance by the nursing students compared to the interns. It is to be noted however that the ADRs reported to the ADR monitoring centre in our institute is very few from the nurses. It may be assumed that the nursing students probably are reporting to the senior nurses through whom the few reports are sent to the ADR monitoring centre.

Various studies have noted the importance of the nursing staff in spontaneous ADR reporting because they spend more time in the wards and it is most likely that the ADRs will first be observed by them or been told to them by the patients. ${ }^{12}$ Nurses give the medicines to the patients and are more in touch with the patients hence more suitable to monitor the patients' response to drugs. They can play a big role in alerting the concerned units about possible ADRs. Hence it is very suitable and logical to involve nurses and encourage them to contribute in ADR reporting system. ${ }^{14}$ In countries where nurses are already participating in the ADR reporting, studies have shown that they indeed contribute positively toward the ADR reporting. ${ }^{15}$

From the above study it appears that there is need to focus on both, the interns and nursing students for reporting ADRs. Interns and nursing students have to be educated and motivated for identifying and reporting ADRs occurring in the patients. More emphasis will have to be put to educate the interns and nursing students to improve the knowledge of occurrence of ADRs and proper practice of pharmacovigilance. Simpler methods for ADR reporting, via SMS or whatsapp to the concerned incharge of the ADR monitoring centre (AMC) in the institute and easy accessibility to ADR forms has to looked for the nursing students and interns. These healthcare professionals may be given targets for reporting number of ADRs and may be given certificate of appreciation for conducting the activity. Practice of ADR monitoring and reporting should be included as part of their curriculum.

It is expected that the results of the current study will be taken into account for designing specific activities for these two specific group of healthcare professionals for the better execution of the pharmacovigilance program in the institutes.

\section{CONCLUSION}

This study showed that even though majority of the healthcare professionals involved in this study had good knowledge and attitude about pharmacovigilance the rate of ADRs reporting by them is very low. Both the groups agreed that pharmacovigilance should be taught in details in their curriculum. The better attitude of the nursing students towards pharmacovigilance hints towards a possibility of better practice in terms of 
pharmacovigilance provided some more guidance is given to them. Even though the ADR reporting of the nurses and interns is poor we should take the advantage of the favourable attitude, specially the nurses, in improving ADR reporting by these important healthcare professionals.

\section{ACKNOWLEDGEMENTS}

Authors would like to thank the nursing students and interns for spending their valuable time to provide the responses to the survey form.

\section{Funding: No funding sources}

Conflict of interest: None declared

Ethical approval: The study was approved by the Institutional Ethics Committee

\section{REFERENCES}

1. WHO: International Drug Monitoring: The Role of the Hospital. Technical Report Series No. 425. Geneva: WHO, 1969.

2. Lazarou J, Pomeranz BH, Corey PN. Incidence of adverse drug reactions in hospitalized patients: a meta-analysis of prospective studies. JAMA. 1998;279(15):1200-5.

3. Baniasadi S, Fahimi F, Shalviri G. Developing an adverse drug reaction reporting system at a teaching hospital. Basic Clin Pharmacol Toxicol. 2008;102(4):408-11.

4. Ramesh M, Pandit J, Parthasarathi G. Adverse drug reactions in south Indian hospital-their severity and cost involved. Pharmacoepidemiol Drug Safe. 2003;12(8):687-92.

5. Beijer HJ, Blaey CJ. Hospitalisations caused by adverse drug reactions (ADR): a metaanalysis of observational studies. Pharm World Sci. 2002;24(2):46-54.

6. Hakkarainen KM, Hedna K, Petzold M, Hagg S. Percentage of patients with preventable adverse drug reactions and preventability of adverse drug reactions a meta-analysis. PLoS One. 2012;7(3):e33236.

7. Subish P, Izham MM, Mishra P. Evaluation of the knowledge, attitude and practices on adverse drug reactions and pharmacovigilance among healthcare professionals in a Nepalese hospital: a preliminary study. Internet J Pharmacol. 2008;6(1):44-9.

8. Green CF, Mottram DR, Rowe PH, Pirmohamed M. Attitudes and knowledge of hospital pharmacists to adverse drug reaction reporting. Br J Clin Pharmacol. 2001;51(1):81-6.

9. Vallano A, Cereza G, Pedros C, Agusti A, Danes I, Aguilera C, et al. Obstacles and solutions for spontaneous reporting of adverse drug reactions in the hospital. Br J Clin Pharmacol. 2005;60(6):653-8.

10. Garg P, Sharma V, Bajaj JK. Assessment of knowledge, attitude and practice of pharmacovigilance among the interns in a tertiary care hospital in northern India- A questionnaire based study. IJMDS. 2017;6(2):1498-503.

11. Gupta SK, Nayak RP, Shivaranjani R, Vidyarthi SK. A questionnaire study on the knowledge, attitude, and the practice of pharmacovigilance among the healthcare professionals in a teaching hospital in South India. Persp Clin Res. 2015;6(1):45.

12. Rehan HS, Sah RK, Chopra D. Comparison of knowledge, attitude and practices of resident doctors and nurses on adverse drug reaction monitoring and reporting in a tertiary care hospital. Indian $\mathbf{J}$ Pharmacol. 2012;44(6):699-703.

13. Qassim S, Metwaly Z, Shamsain M, Hariri YA. Reporting adverse drug reactions: evaluation of knowledge, attitude and practice among community pharmacists in UAE. IOSR J Pharm. 2014;4(4):1723.

14. Hanafi S, Torkamandi H, Hayatshahi A, Gholami K, Javadi M. Knowledge, attitudes and practice of nurse regarding adverse drug reaction reporting. Iran J Nurs Midwifery Res. 2012;17(1):21-5.

15. Ulfvarson J, Mejyr S, Bergman U. Nurses are increasingly involved in pharmacovigilance in Sweden. Pharmacoepidemiol Drug Saf. 2007;16:5327.

Cite this article as: Pawar SR, Gawari NC, Lokhande JM. Evaluation of knowledge, attitude and practice of pharmacovigilance among interns and nursing students in a tertiary care teaching hospital. Int J Basic Clin Pharmacol 2020;9:762-7. 